\title{
Interfaces da gestão ambiental urbana e gestão regional: análise da relação entre Planos Diretores Municipais e Planos de Bacia Hidrográfica
}

\author{
Interfaces of urban environmental management and \\ regional management: analysis of the relationship between \\ Municipal Master Plans and Watershed Plans
}

Renata Bovo Peres ${ }^{[a]}$, Ricardo Siloto da Silva ${ }^{[b]}$

[a] Arquiteta e urbanista, doutora em Engenharia Urbana pela Universidade Federal de São Carlos (UFSCar), professora adjunta do Departamento de Ciências Ambientais da mesma instituição, São Carlos, SP - Brasil, e-mail: renataperes@ufscar.br

[b] Arquiteto e urbanista, doutor em História e Sociedade pela Universidade Estadual Paulista Júlio de Mesquita Filho (Unesp), professor associado do Programa de Pós-Graduação em Engenharia Urbana da Universidade Federal de São Carlos (UFSCar), São Carlos, SP - Brasil, e-mail: rss@ufscar.br

\section{Resumo}

Este artigo relata uma pesquisa que discute como a questão ambiental vem sendo tratada nos instrumentos e práticas de gestão localizadas em dois recortes territoriais: municípios e bacias hidrográficas. Foi analisada a relação da dimensão ambiental com a gestão regional e municipal, por meio dos instrumentos Planos de Bacia Hidrográfica e Planos Diretores Municipais, tendo como locus a Unidade de Gerenciamento de Recursos Hídricos Tietê-Jacaré do Estado de São Paulo. Os objetos de pesquisa selecionados foram o Plano de Bacia Hidrográfica Tietê-Jacaré e os Planos Diretores de Araraquara e São Carlos. A pesquisa abordou as seguintes categorias de análise: unidades de planejamento, instrumentos ambientais contidos no Plano de Bacia e nos Planos Diretores, instâncias de gestão e grau de influência entre os planos analisados. 0 método se pautou em levantamentos, análises bibliográficas e documentais, entrevistas semiestruturadas e questionários. Os resultados obtidos apontaram que o Plano de Bacia Hidrográfica ainda apresenta lacunas e dificuldades para uma atuação mais ampliada. Não reconhece os conflitos de uso da terra e de organização territorial como uma vulnerabilidade que precisa ser enfrentada. Mostraram, ainda, que os Planos Diretores Municipais concentram-se na aplicação dos instrumentos voltados ao parcelamento e ao zoneamento urbano. Nesses planos, as condições e os aspectos ambientais e regionais se apresentam como uma temática periférica e pouco articulada com as demais políticas. As análises procuraram demonstrar a complexa relação entre políticas, instrumentos e instâncias de planejamento e gestão, explicitando os obstáculos que dificultam a aplicação do conceito de gestão territorial integrada.

Palavras-chave: Gestão ambiental urbana. Gestão regional. Planos de Bacias Hidrográficas. Planos Diretores Municipais. Gestão territorial integrada. 


\section{Abstract}

This article details a research work that discusses how environmental issues have been addressed in the instruments and management practices in two territorial areas: municipalities and watersheds. The environmental relationship of the regional and municipal management was analyzed using the Watershed Plans and the Municipal Master Plans, located at the Management Unit of Tietê-Jacaré Water Resources - State of São Paulo. The research subjects selected were the Tietê-Jacaré Watershed Plan and the Master Plans of Araraquara and São Carlos. The study focused on the following analysis categories: the environmental instruments used in the Watershed Plans and the Master Plans, management events and the degree of influence of the plans analyzed. The method was based on surveys, bibliographic and documentary analysis, semistructured interviews and questionnaires. The results showed that there are still gaps and difficulties in the watershed plan to perform a more expanded management planning. It does not acknowledge the conflicts related to land use and territorial organization as a vulnerability that must be addressed. It also showed that the municipal master plans focus on the application of these instruments for urban subdivision and zoning. In these plans, the conditions and regional and environmental aspects are presented as a peripheral issue, which are rarely coordinated with the other policies. The analyses performed sought to demonstrate the complex relationship between policies, instruments and planning and management events, describing the obstacles that interfere with the application of the integrated territorial management concept.

Keywords: Urban environmental management. Regional management. Watershed Plans. Municipal Master Plans. Integrated territorial management.

\section{Introdução}

O momento político brasileiro pós-Constituição recolocou os temas do ordenamento territorial e do planejamento regional, à semelhança de experiências realizadas nos continentes europeu e norte-americano. Ao ressaltar, em seu artigo 21 (BRASIL, 1988), que "compete à União elaborar e executar planos nacionais e regionais de ordenação do território e de desenvolvimento econômico e social", a Constituição Federal de 1988 enfatizou os ordenamentos territorial e regional como instrumentos de planejamento, elementos de organização e de ampliação da racionalidade espacial de ações e políticas públicas. A despeito disso, não houve a efetivação de uma política articulada de ordenamento do território, não significando, contudo, a inexistência de instrumentos que pudessem colaborar para isso. Ao longo do tempo, uma série de sistemas, políticas, planos e programas foram realizados e identificados como de destacado impacto no território. Alguns exemplos: Sistema Nacional de Unidades de Conservação, Sistema Nacional de Recursos Hídricos, Política Nacional de Desenvolvimento Regional, Política Nacional de Meio Ambiente, Política de Desenvolvimento Rural
Sustentável, Sistemas Municipais de Planejamento, Planos Diretores Municipais (e seus instrumentos de gestão territorial urbana), dentre outros.

A Constituição também refletiu a emergência de uma nova abordagem da questão regional no país, supondo uma participação mais ativa dos governos estaduais e municipais na formulação e implementação de políticas de alcance regional. A dimensão ambiental (entendida como recursos naturais, patrimônio natural e cultural, conhecimento e práticas sociais) recebeu certo destaque e começou a ser incluída no discurso e na definição das políticas públicas. Com isso, novos recortes regionais foram criados, como as Unidades de Conservação (UCs) e as Bacias Hidrográficas. A preservação dos recursos hídricos foi uma das temáticas que evidenciou a necessidade de ações regionais conjuntas, uma vez que ultrapassa fronteiras político-administrativas.

A Política Nacional de Recursos Hídricos (Lei n. 9.433/1997) induziu o surgimento de uma nova instância de gestão territorial: os Comitês de Bacias Hidrográficas, que trouxeram, desde sua origem, a característica da participação daqueles que também produzem, usam e habitam no espaço. Foi com essa visão que o Brasil passou a adotar a bacia hidrográfica como um território de gestão e planejamento, 
surgindo a situação dúbia de cooperação e/ou conflito com a gestão das instâncias federativas sobre o mesmo território, em especial os municípios.

Marcos como instrumentos centrais nesse processo, os Planos de Bacia Hidrográfica e os Planos Diretores Municipais foram os objetos centrais na análise do presente trabalho, que procura contribuir com o debate técnico-científico sobre a relação da dimensão ambiental com a gestão regional e urbana. Tendo como objeto empírico a Unidade de Gerenciamento de Recursos Hídricos Tietê-Jacaré do Estado de São Paulo, foram analisados o seu Plano de Bacia e os Planos Diretores de Araraquara e São Carlos, municípios integrantes da Unidade.

Após a discussão sobre os conceitos de unidades de planejamento e gestão regional e local, a pesquisa analisou os objetivos, ações e instrumentos contidos nos planos citados, a competência e situação das instâncias de planejamento e gestão regional e local e o grau de influência entre os instrumentos de gestão. Foram aplicadas quatro técnicas de pesquisa: análises bibliográficas, análises documentais, entrevistas semiestruturadas e questionários.

A escolha da Bacia Hidrográfica Tietê-Jacaré deveu-se ao relevante papel desempenhado pelos recursos hídricos em seu processo de ocupação, que vêm sendo utilizados por usos múltiplos: abastecimento urbano, agricultura, indústria, transporte, energia, turismo e lazer. Alguns desses usos, realizados sem preocupação quanto à sua preservação, acabaram por gerar danos aos recursos naturais resultando perdas significativas, tanto quanto à disponibilidade como quanto à qualidade hídrica.

\section{A gestão regional e os Planos de Bacias Hidrográficas}

A atuação regional sobre questões ambientais tem se ampliado, uma vez que elas, frequentemente, extrapolam as fronteiras das divisões político-administrativas locais. Temas como preservação de recursos hídricos, recuperação da vegetação nativa, práticas agrícolas orientadas para a conservação do meio ambiente e gestão de resíduos vêm sendo tratados evidenciando a necessidade de iniciativas que, de forma implícita ou explícita, envolvam articulação entre a problemática urbana e a regional. Farah (2003, p. 89) evidencia que a experiência recente no campo da gestão pública local no país vem revelando a emergência de iniciativas que procuram integrar o urbano ao regional sob diversos aspectos, destacando o aspecto ambiental como o mais evidente. Uma das temáticas mais consolidadas em termos de gestão regional, e de grande estreitamento com a gestão urbana, é a conservação e preservação dos recursos hídricos.

Em 1997, foi promulgada a Política Nacional dos Recursos Hídricos (BRASIL, 1997), colocando o Brasil entre os países de legislação avançada neste setor, trazendo a constituição de novas instituições e de novas práticas de alcance regional (MUÑOZ ESPINOSA, 2000; PAGNOCCHESCHI, 2003). Novos paradigmas foram construídos, como a conceituação da água como bem de domínio público e recurso natural limitado, dotado de valor econômico; a prioridade do uso dos recursos hídricos em situações de escassez; a participação dos diferentes níveis do poder público, usuários e sociedade civil no processo de tomada de decisão e a descentralização da gestão dos recursos hídricos.

Uma tentativa de dar sustentabilidade e equidade à competição pelos usos da água foi um novo arranjo institucional, consubstanciado na forma do Sistema Nacional de Gerenciamento de Recursos Hídricos (SINGREH). O SINGREH é composto por um Conselho Nacional de Recursos Hídricos, Conselhos Estaduais, órgãos dos poderes públicos federal, estaduais e municipais relacionados com a gestão da água e por um órgão de decisão regional/ local, denominado Comitê de Bacia Hidrográfica, e suas respectivas Agências de Água, impulsionando a necessidade de cooperação entre diferentes esferas administrativas. Dentro deste Sistema, a bacia hidrográfica foi determinada como a unidade territorial de planejamento e gestão. 0 território brasileiro foi dividido em 12 Regiões Hidrográficas e, a partir disso, cada Estado as subdividiu em unidades de gestão.

A divisão hidrográfica, além de direcionar a gestão regional da água, pode influenciar também em outras escalas, já que as bacias contêm os territórios municipais e regiões administrativas. A organização por bacias hidrográficas ainda constitui um grande desafio a ser enfrentado para a implantação dos sistemas de gestão, englobando escalas diferentes, que pretendem ser integradas. 
A Política Nacional de Recursos Hídricos propôs seis instrumentos de gestão: os Planos de Bacias Hidrográficas, o enquadramento dos corpos de água, a outorga dos direitos de uso, a cobrança pelo uso de recursos hídricos, o Sistema Nacional de Informações sobre Recursos Hídricos e a compensação aos municípios.

O Plano de Bacia Hidrográfica, instrumento central de articulação entre o planejamento e a gestão, tem como objetivo geral definir ações de gestão, programas, projetos, obras e investimentos prioritários para este território, dentro de um contexto que inclua os órgãos governamentais, a sociedade civil, os usuários e as diferentes instituições que participam do gerenciamento dos recursos hídricos. Tal Plano também deve levar em consideração todos os demais programas, projetos e estudos que incorporem a proteção dos recursos hídricos na área de abrangência das respectivas bacias hidrográficas, articulando-se com os planejamentos municipais, setoriais e regionais existentes. São, portanto, instrumentos estratégicos, programáticos, de longo prazo, com horizonte de planejamento compatível com o período de implantação de seus programas e projetos.

Como uma das diretrizes gerais de ação do Plano, a Política Nacional dos Recursos Hídricos ressaltou a importância da articulação da gestão da água com a gestão do uso do solo, ao dizer que: "os Poderes Executivos dos Municípios promoverão a integração das políticas locais de uso, ocupação e conservação do solo com as políticas federais e estaduais de recursos hídricos" (BRASIL, 1997). Essa diretriz, necessária e aparentemente óbvia, tem sido de difícil concretização. Para compreender sua implementação, é preciso conhecer quais são as relações entre os instrumentos e os sistemas gestores do ordenamento territorial e aqueles do sistema de gerenciamento dos recursos hídricos por bacias hidrográficas (CARNEIRO; CARDOSO; AZEVEDO, 2008). No entanto, entender as relações que se dão entre gestão de bacias hidrográficas, gestão municipal e a incorporação da dimensão ambiental, não é um processo linear nem, tampouco, evidente. Pressupõe a análise das nuances, das forças atuantes, dos evidentes conflitos, das sobreposições entre processos políticos e econômicos, assim como dos instrumentos normativos e jurídicos que os condicionam.

\section{A gestão ambiental urbana e os planos diretores municipais}

Diversos autores consideram que, nos últimos anos, tem havido um significativo avanço no que se refere à criação e implementação de novos instrumentos de gestão urbana-ambiental nas cidades. A experiência recente sugere, também, haver ganhos significativos na adoção, no planejamento urbano e rural, de instrumentos originalmente concebidos na esfera da gestão ambiental (CARTER; KREUTZWISER; DE LOË, 2005; SILVA; PORTO, 2003). Entretanto, embora o discurso da proteção esteja presente em muitas falas de gestores que atuam no desenvolvimento das cidades, a questão ambiental apresenta-se, ainda, como uma constante fronteira de embates e tensões. Esses ocorrem, pois os momentos institucionais e as trajetórias percorridas pela política ambiental e pela política urbana foram historicamente distintos. Desse modo, mesmo que haja avanços relacionados às interlocuções e articulações ambiental-urbanas, a prática recente do planejamento urbano vem trazendo novas questões e reflexões que merecem aprofundamento para serem enfrentadas. Uma delas passa pela compreensão de que a escala regional é, na maioria dos casos, mais adequada para tratar e compreender os problemas relacionados aos recursos hídricos, às áreas de proteção da vegetação, aos processos de degradação do solo etc.

Até os anos de 1990, a dimensão ambiental não era inserida como elemento estruturante nas diretrizes e propostas no campo da gestão urbana no Brasil. Mesmo diante dos crescentes problemas socioambientais, fruto dos processos inadequados de uso e ocupação do solo, essa era uma temática apenas tangenciada, e tratada de forma superficial pelas políticas municipais. Havia uma despolitização da análise, das práticas e representações do ambiente natural, sendo a temática ambiental reconhecida nos planos diretores apenas de forma setorial (COSTA, 2008, p. 83). Raramente apareciam algumas das mais candentes questões ambientais urbanas, como ocupações de áreas de mananciais, encostas e fundos de vale. No fim dos anos 80 e início dos 90, inspiradas por discussões de âmbito internacional, questões como a conservação e a preservação dos recursos naturais e o papel do homem integrado ao meio começavam a ser inseridas na discussão sobre 
qualidade de vida das cidades. A partir da realização da Eco-92, o debate sobre as relações entre as questões urbanas e ambientais passou a se dar num ambiente menos restrito e tendo como interlocutores um conjunto de novos atores.

Com a aprovação do Estatuto da Cidade (EC), em 2001, a dimensão ambiental é reforçada como elemento importante para o planejamento urbano, a partir de uma visão menos setorial e cada vez mais abrangente das políticas públicas. Instituído pela Constituição Federal, o EC caracterizou o Plano Diretor Municipal em um novo e estratégico patamar. Instrumento central, com o qual todos os demais instrumentos de política urbana deveriam guardar estreita relação, diferia dos planos diretores de desenvolvimento urbano das décadas de 1970 e 1980, pelo seu caráter estratégico e participativo. Apesar de citada nas diretrizes da lei do EC, a questão ambiental encontrou pouco amparo nos instrumentos instituídos, voltados mais ao combate à especulação imobiliária.

Decorridos dez anos de implementação do Estatuto, análises consideraram que, em âmbito nacional e, em alguma medida, nos estados e municípios, a regulação ambiental revelou uma mudança de discurso através de mecanismos integrados, como o caso do licenciamento ambiental de empreendimentos urbanos, do Estudo de Impacto de Vizinhança e da licença urbanística integrada. Contudo, a questão ambiental ainda aparece desvinculada da política de ordenamento territorial e das questões de infraestrutura urbana. A grande dificuldade em romper a lógica setorial e na vinculação da temática ambiental à Agenda Verde ainda persiste (COSTA et al., 2011, p. 184).

Desse modo, mesmo que pareça haver convergências crescentes da dimensão ambiental, dentro do universo da gestão urbana, este ainda é um processo em contínua construção e disputa. Há dificuldade de integração das diferentes racionalidades associadas às políticas urbana e ambiental; há falta de articulação entre as leis e os instrumentos normativos urbanos e ambientais municipais, estaduais e federais; há tensões entre o uso público e privado dos recursos bióticos e abióticos da cidade e de seu entorno; persistem a setorialização no tratamento da questão ambiental, a desconexão com o setor de planejamento urbano e a não superação dos limites administrativos. Desafios que extrapolam, muitas vezes, a questão institucional e de gestão e que incluem interesses antagônicos, desrespeito às legislações existentes e opções claras por formas de ocupações que não atendem às condições do território e sim aos interesses privados e especulativos.

\section{Um estudo visando à compreensão das interfaces}

Este artigo analisa a região central do Estado de São Paulo, especificamente na Unidade de Gerenciamento de Recursos Hídricos Tietê-Jacaré. Considerado, em âmbito nacional, como um protagonista na criação de um Sistema Integrado de Gestão dos Recursos Hídricos (SIGRH), o Estado de São Paulo assiste hoje ao significativo crescimento da degradação de suas águas superficiais e subterrâneas, sobretudo em áreas urbanas densamente povoadas, além da grande pressão e disputa de diversos setores sobre os usos da água.

Para a criação do Sistema Integrado de Gestão dos Recursos Hídricos, o território paulista foi dividido em 22 Unidades de Gerenciamento dos Recursos Hídricos (UGRHIs), bases territoriais dos Comitês de Bacias Hidrográficas. A partir dessa estruturação, houve a abertura de espaços institucionais para uma integração regional dos órgãos e entidades governamentais e não governamentais, surgimento de novos agentes no processo de decisões e maior publicização dos assuntos e problemas ligados aos recursos hídricos. A criação do SIGRH, no entanto, não contemplou a integração de órgãos como os de planejamento urbano, saneamento e mobilidade.

Do ponto de vista da disponibilidade e qualidade hídricas, a Bacia Hidrográfica do Tietê-Jacaré (UGRH-13) é considerada crítica, pois já vem refletindo e reproduzindo o ocorrido na bacia a montante - a do Alto Tietê (onde se localiza a cidade e parte da região metropolitana de São Paulo). A intensificação da urbanização e o acelerado crescimento populacional na Bacia Hidrográfica TietêJacaré acarretaram diversos impactos relacionados à insuficiência de infraestrutura urbana, bem como àqueles ligados ao meio físico: erosão, assoreamento, inundações, poluição das águas e perda de vegetação. Esses foram, muitas vezes, reflexos da ausência de políticas públicas adequadas de uso e ocupação 
do solo dos municípios que compõem a região. Ao todo, 34 municípios pertencem à UGRHI-13, totalizando 1.480.934 milhões de habitantes, representando 3,6\% do total paulista (IBGE, 2010). Embora 96\% da população da Bacia do Tietê-Jacaré residam nas cidades, apenas $4 \%$ do território da UGRHI é urbano. Trata-se de uma região onde há predominância de atividades rurais, em termos territoriais e de usos da água.

Seu Plano de Bacia Hidrográfica traz o objetivo de orientar as intervenções e o controle do uso da água desta UGRHI. 0 processo de elaboração do Plano de Bacia Tietê-Jacaré iniciou-se no ano de 2004 e foi aprovado em dezembro de 2008. A elaboração considerou os horizontes de curto (2008-2011), médio (2012-2015) e longo prazos (2016-2019) e apontou as seguintes finalidades: 1) atualizar dados e informações sobre a bacia hidrográfica; 2) difundir os resultados contribuindo para o entendimento e conscientização dos atores e setores envolvidos com o Comitê acerca da situação dos recursos hídricos da UGRHI; 3) fomentar a ideia de estabelecimento compartilhado do planejamento entre o Comitê e sociedades locais; 4) conscientizar os atores detentores de informações de interesse público para a sua disponibilização.

Utilizando-se de métodos como entrevistas semiestruturadas e questionários, foram consultados para esta pesquisa representantes de órgãos ligados à gestão ambiental dos 34 municípios pertencentes à UGRHI-13, a fim de realizar uma análise ampliada sobre a percepção e a opinião sobre a importância da articulação regional e a contribuição do Plano de Bacia para a gestão municipal. Também foram analisados, de forma detalhada, os Planos Diretores dos municípios de Araraquara e São Carlos. A escolha desses municípios justificou-se por, dentre os pertencentes à Bacia Hidrográfica do Tietê-Jacaré, serem os que exercem fortes influências regionais. Fundamentada em pesquisas bibliográfica e documental, procurou-se buscar as compatibilidades, as divergências, as limitações e as possíveis articulações entre os dois instrumentos: Plano de Bacia e Plano Diretor. A análise realizada para o Plano de Bacia pautou-se nas categorias: definição das unidades de planejamento e gestão regional; objetivos, ações e instrumentos de caráter ambiental contidos no Plano de Bacia; competência e atuação das instâncias de planejamento e gestão regional; e grau de influência dos Planos Diretores no Plano de Bacia. A análise realizada para os Planos Diretores pautou-se nas categorias: definição das unidades de planejamento e gestão local; objetivos, ações e instrumentos de caráter ambiental contidos nos Planos Diretores; competência e atuação das instâncias de planejamento e gestão local; e grau de influência do Plano de Bacia no Plano Diretor.

\section{Análise do Plano de Bacia Hidrográfica Tietê-Jacaré}

O Plano de Bacia Hidrográfica Tietê-Jacaré evidenciou ser um instrumento de planejamento regional de grande potencial, sobretudo nos aspectos relacionados à gestão da água. Sua aprovação significou expressivo avanço, contribuindo para que o Comitê dispusesse de seu mais importante instrumento para a gestão. Embora apresente esse potencial, é um documento ainda centrado somente no corpo hídrico, com poucas análises, proposições e interlocuções com o uso da terra. As entrevistas realizadas reconheceram se tratar de um instrumento norteador das ações para a região, embora ainda haja uma distância entre o grande número de metas traçadas e a prática cotidiana de gestão no Comitê, em que estão presentes dificuldades em captação de recursos, cumprimento de prazos, participação pública, controle social e divulgação.

A principal Unidade de Planejamento e Gestão Regional que definiu as fronteiras de atuação do Plano de Bacia do Tietê-Jacaré foi, certamente, a referida bacia hidrográfica. De acordo com o diagnóstico, verifica-se que ainda há uma grande dificuldade em se extrair informações por bacia e sub-bacias, uma vez que a maioria dos dados analisados foi obtida por meio de dados municipais.

0 Plano de Bacia propôs um conjunto de 103 Metas (6 Estratégicas, 22 Gerais, 75 Específicas) e 190 Ações Recomendadas. Fazendo uma análise mais direcionada à articulação regional-municipal, as ações apontadas priorizam as temáticas setoriais mais conhecidas: proteção das áreas verdes, APPs e mananciais; tratamento dos esgotos, disposição adequada de resíduos e uso racional da água para abastecimento. Há também preocupação com os processos erosivos e a implantação adequada das atividades industriais e minerárias. 0 Plano 
Diretor Municipal é apontado como o principal instrumento regulador e articulador dessas ações e para a avaliação dos efeitos da urbanização sobre os recursos hídricos.

As análises dos documentos e o contato com entrevistados demonstraram que o Comitê de Bacia Tietê-Jacaré apresenta-se como um espaço político e de gestão da água com reconhecida importância na região. Contudo, ainda é condicionado aos interesses de órgãos e representantes voltados aos setores de maior peso, como o setor elétrico e agrícola, havendo desigualdade de representatividade nas tomadas de decisões. Além disso, ainda carece de maior estrutura para uma efetiva estruturação de um Sistema de Gestão Regional. A participação dos municípios é ainda muito incipiente no tocante à integração e ao desenvolvimento de propostas a ações conjuntas de planejamento e gestão regional e local. Essas discussões ocorrem nas Câmaras Técnicas, espaço em que as Secretarias Municipais de Meio Ambiente, de Obras e Serviços e de Planejamento Urbano participam, representando o prefeito, embora sem direito a voto. Os órgãos e as autarquias de água são os que mais participam efetivamente do Comitê e os mais organizados em relação à elaboração de projetos e captação de recursos.

Além do instrumento Plano Diretor Municipal, o Plano de Bacia indicou também os instrumentos de ordenamento territorial municipal que incorporariam as discussões feitas localmente sobre a questão ambiental da preservação da qualidade e quantidade de água: Planos de Conservação de Água e Combate à Perda, Planos de Macrodrenagem, Planos de Combate à Erosão; Planos Diretores de Esgoto; Planos de Gerenciamento de Resíduos Sólidos e Planos de Gerenciamento de Risco.

Concluiu-se que o Plano de Bacia Hidrográfica do Tietê-Jacaré avançou no que diz respeito à compilação de elementos técnicos, metas e ações que visam à proteção dos recursos hídricos desse território, embora ainda pouco considere a avaliação e a articulação com os instrumentos de ordenamento territorial e de uso e ocupação do solo e a importância da instância municipal, não apenas como usuária, mas também como cogestora da água e dos recursos ambientais.

Um exemplo de sistema que poderia ser mais articulado nas três escalas de planejamento (e também regionalmente) é o Sistema Nacional de Unidades de
Conservação (SNUC) (Lei Federal n. 9.985/2000), que integra as Unidades de Conservação federais, estaduais e municipais sob um só marco legal. 0 Plano de Bacia Tietê-Jacaré toma como referência as Áreas Protegidas consideradas pelo SNUC e ressalta que a autonomia das diferentes escalas do poder público para criar essas áreas deve ser exercida de forma articulada, visando a complementar ações de conservação em diferentes biomas, considerando os contextos locais. Menciona também que deve ser feito um programa de esclarecimento e incentivo à criação de Unidades de Conservação no âmbito municipal, embora não faça nenhuma relação com as Áreas de Especial Interesse Ambiental, urbanas ou rurais, propostas nos Planos Diretores Municipais de Araraquara e São Carlos, por exemplo.

\section{Análise dos planos diretores de Araraquara e São Carlos}

O Plano Diretor de Araraquara apresentou princípios e diretrizes atrelados com a dimensão ambiental procurando apontar instrumentos que visassem uma política de meio ambiente municipal para além da abordagem preservacionista. Utilizou os fundamentos do Estatuto da Cidade e da Agenda 21 e adotou a bacia hidrográfica, subdividida em seis microbacias, como Unidade de Planejamento e Gestão do Território, tendo em vista as características do município. Duas concepções de Macrozoneamento foram estabelecidas, o Zoneamento Urbano dividiu-se em Zonas Ambientais e Zonas de Estruturação Urbana Sustentável e também foram definidas Áreas Especiais. O Plano evidenciou uma tentativa de convergência da questão ambiental com a urbana, ressaltando a importância dos Estudos de Impacto e Viabilidade Urbanística e do Relatório de Impacto e Viabilidade Urbanística, compreendidos como instrumentos que poderiam contribuir para o uso e ocupação do solo considerando os seus aspectos ambientais. Além desses, o Plano também congregou os Estudos de Impacto Ambiental e os Licenciamentos Ambientais. Há evidências também para uma visão contemporânea de interpretação da função social da propriedade a partir de propostas para usos coletivos e ambientalmente importantes como os espaços rurbanos voltados para um tipo de agricultura local para abastecer o consumo urbano. 
Contudo, essas novas concepções não foram incorporadas aos processos cotidianos de gestão e a expansão da cidade vai, justamente, na direção desses espaços. A preocupação, portanto, em buscar conter uma das maiores fragilidades ambientais do Município de Araraquara, que é o espraiamento e a presença dos vazios urbanos, parece não ter obtido resultados positivos.

Outro instrumento proposto, considerado inovador, que tratou da proteção das redes hídricas municipais foram os Corredores de Integração Ecológica (CIECOS). Nesses locais, além da faixa de 30 metros non aedificandi prevista na Legislação Federal, o município consideraria, ao longo de alguns de seus rios, uma faixa adicional de 70 metros, non aedificandi, na qual seria permitido o uso apenas de áreas verdes provenientes de empreendimentos urbanísticos para a implantação de Parques Lineares Urbanos. A proposta de formação de um Sistema de Gestão Ambiental Municipal feita pelo Plano Diretor de Araraquara apresentou intenções favoráveis à integração urbano-ambiental e regional, envolvendo as instâncias: Secretaria Municipal de Desenvolvimento Urbano, Conselho Municipal de Política Urbana Ambiental, Conselho Regional das Cidades, Agência de Desenvolvimento Regional, Fundo e Consórcios Intermunicipais, Secretarias e Câmara Municipal. Em relação à questão hídrica, o Plano também indicou a criação do órgão Defensoria das Águas, responsável por propor e garantir a aplicabilidade das leis e normas voltadas ao controle da qualidade da água, bem como à preservação do patrimônio hídrico municipal. Propôs que a política municipal fosse articulada com as políticas ambientais, de âmbito regional e estadual, por meio do Sistema Integrado de Gerenciamento de Recursos Hídricos. Previu também a elaboração de Planos Estratégicos Regionais, que poderiam estimular a implantação de uma Rede de Cidades para a integração e complementariedade do desenvolvimento urbano e regional, a partir de uma Agência de Desenvolvimento Regional, a serem incorporados no Sistema Municipal de Planejamento.

O Plano Diretor de Araraquara ficou regionalmente conhecido por enfatizar a dimensão ambiental. Contudo, por excessos de terminologias e falta de entendimento de alguns conceitos, uma de suas maiores fragilidades se mostrou na passagem do planejamento para a gestão, visto que grande parte desses instrumentos não foi implementada ou regulamentada. As metas concretas para uma política ambiental foram remetidas para regulamentação específica, expressas no Plano Diretor de Gestão e Saneamento Ambiental, sem previsão para ser elaborado. Assim, esse Plano Diretor evidencia a necessidade de realizar um processo de planejamento participativo e que não permita grande distanciamento entre discurso e prática, pensado e estruturado em cima de uma base fundamentada na cidade real.

O Plano Diretor de São Carlos apresentou avanços, principalmente relacionados ao planejamento e à gestão do município e ao disciplinamento do parcelamento do solo. Foi um Plano mais objetivo ao contemplar os instrumentos propostos pelo Estatuto da Cidade, e menos audacioso, no sentido de incorporar outros conceitos de planejamento e gestão. Pelo fato de ter sido um Plano fruto de uma construção menos personalizada (que, logicamente, acabou sendo resultado de acordos e negociações dos diversos segmentos que atuam na produção do espaço), de certa forma, foi incorporado à gestão do desenvolvimento urbano e vem contribuindo para o ordenamento da cidade, sobretudo no que tange aos aspectos cotidianos de aprovação e controle do uso e ocupação do solo. Dois instrumentos propostos para efetivar a recuperação dos investimentos do poder público de que tenha resultado a valorização de imóveis urbanos foram aplicados: a Outorga Onerosa do Direito de Construir e a Outorga Onerosa de Alteração de Uso do Solo. Esta última pode ser considerada um instrumento inovador para a área rural, mas terá que enfrentar também a existência, neste meio, de parcelamentos irregulares já consolidados.

No que tange aos aspectos ambientais, este foi um Plano que trouxe elementos importantes para a proteção ambiental e dos recursos hídricos em escala urbana e municipal, sobretudo ao tratar das áreas de mananciais de abastecimento público. Visando a ordenar a ocupação e orientar a produção do espaço, o território do Município foi dividido em Macrozonas, Zonas e Áreas de Especial Interesse. A dimensão ambiental e, em específico, a questão da proteção dos recursos hídricos foram elementos que contribuíram para a definição das unidades de planejamento e gestão para o Plano Diretor de São Carlos, principalmente para áreas localizadas fora 
do perímetro urbano. Instrumentos que poderiam servir como importantes ferramentas para a proteção ambiental não foram utilizados ou vêm sendo usados de forma a gerar certo descrédito, como a Transferência do Direito de Construir e o Estudo de Impacto de Vizinhança. Outra lacuna evidenciada foi a falta de interlocução com as escalas, instâncias e instrumentos regionais. São Carlos tangencia e faz limites com importantes fragmentos de preservação ambiental e áreas de turismo ecológico e pertence a dois Comitês de Bacia. Ações consorciadas que visem ser compartilhadas com os municípios pertencentes à Bacia são, portanto, fundamentais. Assim, embora a "gestão do cotidiano" tenha de fato se incorporado e esteja evidente em parte da opinião dos segmentos que atuam na cidade, o Plano Diretor de São Carlos ainda traz consigo lacunas e ambiguidades que precisam ser superadas. Uma delas é a permissividade de ocupação de áreas com grandes fragilidades socioambientais. Outra é a amplitude e o interesse pela ampliação de zonas localizadas em áreas rurais consideradas de expansão urbana. A gestão do cotidiano pode agora almejar uma gestão mais inovadora, no sentido de ousar e experimentar os demais instrumentos e não se acomodar com o que já foi incorporado como mecanismo da máquina administrativa.

\section{As interfaces possíveis: interlocuções e perspectivas para a gestão territorial integrada}

As análises que percorreram as reflexões deste trabalho sinalizaram um conjunto de condições que podem favorecer o diálogo entre gestão regional por bacias hidrográficas e gestão ambiental urbana. A partir dos resultados, foi possível destacar diretrizes voltadas à articulação dos instrumentos estudados, procurando contribuir para o aperfeiçoamento da gestão urbana e regional integradas.

Reconhecimento da Bacia Hidrográfica como Unidade de Planejamento e Gestão Municipal

Da mesma forma que outras políticas regionais estão adotando a bacia hidrográfica como escala de planejamento, isso também pode ocorrer, de forma integrada, na gestão municipal, por exemplo, um Macrozoneamento Municipal por microbacias hidrográficas, considerando elementos e critérios ambientais, articulado com os municípios limítrofes e com o Plano de Bacia. De forma complementar, o Zoneamento Urbano também pode considerar, juntamente com aspectos sociais e de infraestrutura, elementos da gestão hídrica na delimitação de suas zonas urbanas e nos critérios de parcelamento, ocupação e expansão. Destacam-se, nesse caso, as Áreas Especiais de Fundos de Vale, para as quais se pode definir padrões diferenciados. Nelas, pode ser incentivado o uso por meio de parques, áreas verdes e de lazer, buscando conciliar proteção ambiental e o uso público e coletivo. 0 potencial construtivo dessas áreas poderia ser trocado, como solo criado ou índices de aproveitamento urbano, em áreas mais valorizadas na cidade.

Repensar os espaços rurais e as fronteiras urbanas diante de suas transformações para a definição de novos instrumentos e novas Unidades de Planejamento e Gestão Municipais

Urbano e rural são duas categorias que não se dividem mais tão claramente. As zonas de fronteira rural-urbano podem servir como uma reserva de área para empreendimentos imobiliários, mas podem ser também uma potencialidade de usos mais sustentáveis do território que caminhariam na direção de um espaço mais múltiplo, contrário aos processos de deslegitimização das funções sociais da terra.

Novos instrumentos podem ser pensados. Um exemplo que vem sendo realizado em municípios do Estado de São Paulo são os Planos de Desenvolvimento Rural Sustentável. Contudo, eles são descolados das políticas urbanas e se voltam principalmente à indicação de ações para novas oportunidades econômicas e potencialidades das principais cadeias produtivas. A competência do município de legislar sobre o rural deve ser mais clara e melhor definida, no sentido de pensar quais são as ações possíveis e prioritárias, como o controle e a regularização fundiária; a regulação de culturas; a definição de zonas especiais, de preservação ambiental e de interesse histórico e cultural; o disciplinamento do uso e ocupação nos distritos rurais; a regulação das atividades de turismo e lazer e a 
adoção de mecanismos para garantir que a propriedade rural atenda a sua função social.

Aperfeiçoamento dos Termos de Referência que orientam a elaboração do conteúdo mínimo dos Planos de Bacia Hidrográfica

O Plano de Bacia Hidrográfica, nos moldes atuais, é uma peça excessivamente técnica e que vem sendo pouco incorporada no dia a dia das instâncias de gestão dos recursos hídricos. Tem se apresentado mais como um diagnóstico da situação ambiental do que um instrumento indutor de políticas de fato. Também vem sendo construído por instâncias que atuam com um olhar muito direcionado aos aspectos de qualidade e quantidade da água, dando pouca atenção aos aspectos de gestão do uso e da ocupação do território. 0 desafio, portanto, é aproximar o Plano de Bacia Hidrográfica de um Plano de Ação para a Bacia. Para isso, os parâmetros que definem seu conteúdo mínimo podem ser revistos, no sentido de incorporar estudos e aproximações com os instrumentos municipais, dentre outros aspectos.

Indicação de instrumentos e ações específicas voltadas aos municípios nos Planos de Bacia Hidrográfica

As ações apontadas pelo Plano de Bacia Hidrográfica, relativas aos municípios, ainda são genéricas e desarticuladas com as ações propostas nos respectivos Planos Diretores. Elas acabam por priorizar as temáticas setoriais mais conhecidas, como: recuperação de áreas verdes, tratamento de esgotos, destinação adequada de resíduos sólidos e proteção e conservação dos recursos hídricos. Não há diretrizes ou ações específicas voltadas à tentativa de reversão dos processos inadequados de uso e ocupação do solo que ocorrem nos territórios municipais e que afetam a bacia como um todo. Desse modo, durante o processo de elaboração dos Planos de Bacia Hidrográfica devem ser considerados diagnósticos em escala municipal e analisados os conteúdos de todos os Planos Diretores dos Municípios pertencentes à bacia, para que se encontrem características comuns, sobreposições e para que possam indicar ações conjuntas e prioritárias. Essas ações podem ser consideradas como critérios de priorização de distribuição de recursos no âmbito do Comitê de Bacia.

Incorporação de diretrizes e instrumentos específicos para os recursos hídricos e de instrumentos originários da política ambiental nos Planos Diretores Municipais

Do mesmo modo que os Planos de Bacia Hidrográfica devem apontar ações mais específicas e integradas aos municípios, os Planos Diretores também devem incorporar as diretrizes propostas no Plano de Bacia Hidrográfica relativas à sua área de influência. As questões referentes aos recursos hídricos nos Planos Diretores atuais somente indicam diretrizes gerais para proteção dos mananciais e matas ciliares, preservação dos fundos de vale ou poluição dos corpos d'água. Não está claro de que forma essas diretrizes se materializam em instrumentos concretos de intervenção e de controle do uso do solo. Os instrumentos originários da política ambiental podem ser incorporados, nesse sentido. O Licenciamento Ambiental e o Estudo de Impacto de Vizinhança podem contribuir com a atuação do município na proteção ambiental e conservação dos recursos hídricos, em particular. Há, porém, necessidades de aprofundamento e adequação destes instrumentos em escala municipal, principalmente para as atividades mais complexas de produção do espaço, como a construção de loteamentos, a realização de obras de infraestruturas urbanas ou, até mesmo, a expansão de atividades rurais. Há também alguns instrumentos, que vêm sendo pouco utilizados, mas que podem contribuir com a proteção dos recursos hídricos, como a Transferência do Direito de Construir, o Direito de Preempção e as Operações Urbanas Consorciadas. Juntamente, podem ser previstos mecanismos econômicos diferenciados que contribuiriam para a arrecadação e estruturação de um Sistema de Gestão Ambiental Municipal.

Consideração de variáveis ambientais nas diretrizes de parcelamento e nos parâmetros de Uso e Ocupação do Solo

Algumas diretrizes de Parcelamento, Uso e Ocupação do Solo, presentes nos Planos Diretores, 
vêm procurando acrescentar preocupações de caráter ambiental que podem contribuir para redução de áreas de inundação, dos processos erosivos e melhoria da qualidade dos recursos hídricos. Um exemplo é a criação dos Coeficientes de Permeabilidade e de Cobertura Vegetal, a serem obrigatoriamente aplicados em determinadas áreas do município, proporcionando redução da impermeabilização do solo e redução do escoamento superficial. Outro caso é a exigência, para os novos parcelamentos, de implantação de mecanismos de drenagem sustentável, como construção de bacias de retenção de água e pavimentos permeáveis. Entretanto, ainda há desafios que merecem ser aperfeiçoados, como a vinculação, nos Planos Diretores, entre projeto de parcelamento do solo e desenho urbano. Para isso, podem ser indicados padrões arquitetônicos adequados às características espaciais e socioambientais dos territórios a serem ocupados.

Maior aproximação das instâncias municipais de meio ambiente e de desenvolvimento urbano com os Comitês de Bacia Hidrográfica

Os Conselhos Municipais de Meio Ambiente são espaços de discussão e deliberação das questões que tangenciam a área ambiental na escala municipal. Essas instâncias poderiam estar mais próximas do respectivo Comitê de Bacia Hidrográfica e das ações de âmbito regional. A participação de representantes do Comitê de Bacia Hidrográfica nos Conselhos pode vir nessa direção. Por outro lado, o Comitê de Bacia pode interagir mais com as instâncias municipais ligadas à área ambiental e de planejamento urbano. 0 debate e difusão do Plano de Bacia Hidrográfica e o envolvimento dos profissionais efetivos de órgãos municipais de meio ambiente e desenvolvimento urbano podem resultar em uma maior continuidade do processo de articulação regional. A formação de Consórcios Intermunicipais também contribui para o fortalecimento de uma visão regional entre as instâncias locais.

No âmbito municipal, os setores ambientais-urbanos municipais podem atuar de forma mais articulada na gestão do parcelamento e no uso e ocupação do solo envolvendo atividades imobiliárias, agrícolas, turísticas, industriais, de controle de cheias, de moradias etc; na gestão das águas, envolvendo atividades relacionadas aos seus múltiplos usos; na gestão de parques, áreas verdes, mananciais; e na gestão do saneamento ambiental. A condução e análises dos processos de Licenciamento Ambiental Municipal e dos Estudos de Impacto de Vizinhança podem ser elementos integradores entre essas instâncias.

Melhoria da capacidade institucional do sistema de planejamento e gestão municipal

Uma das principais fragilidades dos municípios na busca de maior participação e aprofundamento nas questões ambientais é a ausência de uma estrutura institucional adequada, profissionais com vínculos informais, precária estrutura física e administrativa e falta de instrumentos de incentivo à regularização. A instituição de um Sistema de Gestão Ambiental Municipal pode ser um caminho profícuo, na perspectiva de se constituir uma estrutura organizacional, diretrizes normativas e operacionais, implementação de ações gerenciais, relações institucionais e espaços participativos. Além disso, trata-se de uma esfera capaz de transcender o nível local para interagir com outras esferas de gestão ambiental regional, estadual e nacional. Para os municípios de maior porte, uma das possibilidades também seria a criação de um órgão regulador e de planejamento independente. 0 aperfeiçoamento desse Sistema de Gestão Ambiental Municipal deve ser também acompanhado pela criação de um Sistema de Informação que seja contínuo. Em termos regionais, a implementação de uma rede de monitoramento definindo os parâmetros e patamares para a qualidade dos corpos d'água também é fundamental, no sentido de identificar as principais causas e as propostas de prevenção e remediação. A criação da Agência de Bacia pode ser um caminho para a integração e gestão das informações regionais e municipais.

\section{Conclusões}

As análises que percorreram as reflexões deste trabalho procuraram demonstrar a complexa relação entre as políticas, os processos, os instrumentos e as instâncias de planejamento e gestão municipal e regional, explicitando os obstáculos técnicos, 
político-institucionais e legais que dificultam a aplicação do conceito de gestão territorial integrada. A gestão por bacias hidrográficas vem redesenhando a relação do municipal e com o regional e mostrando que o país necessita de organizações intermediárias, entre Estado e Município, que possam corporificar a construção de projetos conjuntos ao alcance da participação real dos grupos sociais neles interessados. Essas instituições complementariam, e não substituiriam, o papel do Estado, principal responsável pela gestão ambiental pública (PERES, 2012).

As análises também verificaram que há um conjunto de condições dentro de instrumentos de gestão regional e urbana que favorecem o diálogo e maior articulação. Contudo, ainda há um percurso a ser percorrido para o estreitamento dos possíveis diálogos e articulações. Nesse sentido, os Planos Diretores Municipais e os Planos de Bacia Hidrográfica são instrumentos de grande potencial, mas devem ser vistos como um começo e não como um fim. Não é apenas pela articulação de instrumentos técnicos que se atinge a gestão integrada. Os desafios se situam, sobretudo, no campo político. Para que esses Planos efetivamente cumpram seus objetivos, deve-se pensar o conceito de planejamento como um processo dinâmico em que a constante percepção, interações e concretização das oportunidades e das suas materializações, por meio de negociações político-institucionais, constituam estratégias de implementação, acompanhamento e revisão. Os Planos não resolvem por si sós os problemas regionais ou municipais. Dependem, fundamentalmente, da participação política da sociedade, tendo em vista a prática da cidadania e a construção de um pacto social. Tal caminho não é simples. Pelo contrário, os instrumentos contidos nesses planos propõem implementar conceitos que contrapõem-se ao modelo prevalecente no país, dominado pelo desenvolvimento urbano como geração de negócios e oportunidades para poucos. Um dos grandes "nós" dessa questão está, portanto, nos conflitos entre interesses privados e interesses públicos condicionados pela lógica do capital. Para tentar reverter essa lógica, os Planos devem servir como um instrumento de mediação de conflitos e o planejamento precisa ser efetivamente incorporado na gestão, sendo adequado à realidade e à dinâmica desse sistema de gestão. É no nível da gestão que se estabelece a cidade real, a dualidade entre legalidade e ilegalidade. E os instrumentos legais disciplinadores do uso do solo, para terem êxito, têm que estar incorporados na rotina decisória e pactuados com o conjunto da sociedade. A retomada da discussão da formulação de uma Política de Ordenamento Territorial que possa propor novas unidades e atuar em várias escalas de planejamento, e que incorpore os Planos Diretores dentro dessa lógica, repensando e recolocando, inclusive, seu papel, pode contribuir para tal.

Em se tratando da dimensão ambiental, não há dúvida em relação à importância dos governos locais no ordenamento do território e às consequências de sua gestão na conservação ambiental. Dentro disso, o Plano Diretor pode ser um caminho inquestionável e profícuo para a efetividade da proteção ambiental, desde que extrapole a escala intraurbana e o foco dos aspectos ligados à agenda verde $\mathrm{e}$ apresente uma visão de gestão ambiental atrelada à gestão do uso e da ocupação do solo. Ou seja, a dimensão ambiental deve migrar de uma lógica setorial para uma lógica territorial. Sem essa postura, o "ambiental" resultará em mera retórica ou discurso vazio.

Existe um campo ainda pouco explorado, dentro da gestão municipal, sobre as potencialidades de aplicação dos novos instrumentos contidos nas políticas ambientais. A regulação ambiental de forma mais ampla vem experimentando uma desejável, ainda que difícil, articulação com a regulação urbanística. Identificar as relações entre a gestão de bacias hidrográficas e as dinâmicas de gestão urbana e articular os instrumentos específicos do sistema de gerenciamento dos recursos hídricos com instrumentos de regulação que agem sobre o território municipal pode ser um começo promissor para isso. A criação de estruturas consorciadas, não apenas entre municípios próximos, mas também entre municípios de uma mesma bacia hidrográfica, o compartilhamento institucional voltado para a integração das ações e políticas públicas territoriais e a articulação entre a sociedade civil, congregando seus interesses em torno de um pacto para a gestão do território, são as bases da efetivação de uma gestão territorial integrada.

\section{Referências}

BRASIL. Constituição (1988). Constituição da República Federativa do Brasil. Brasília: Senado Federal, 1988. 
BRASIL. Lei n. 9.433, de 8 de janeiro de 1997. Institui a Política Nacional de Recursos Hídricos, cria o Sistema Nacional de Gerenciamento de Recursos Hídricos, regulamenta o inciso XIX do art. 21 da Constituição Federal, e altera o art. $1^{\text {o }}$ da Lei n. 8.001, de 13 de março de 1990, que modificou a Lei n. 7.990, de 28 de dezembro de 1989. Diário Oficial [da] República Federativa do Brasil, Brasília, DF, 9 jan. 1997. Disponível em: <http://www. planalto.gov.br/ccivil_03/LEIS/19433.htm>. Acesso em: 11 out. 2013.

BRASIL. Lei n. 9.985, de 18 de julho de 2000. Regulamenta o art. 225, § 1ํㅡㄹ incisos I, II, III e VII da Constituição Federal, institui o Sistema Nacional de Unidades de Conservação da Natureza e dá outras providências. Diário Oficial [da] República Federativa do Brasil, Brasília, DF, 19 jul. 2000. Disponível em: <http://www.planalto.gov.br/ccivil_03/leis/19985.htm>. Acesso em: 11 out. 2013.

CARnEIRO, P. R. F.; CARDOSO, A. L.; AZEVEDO, J. P. S. Planejamento do uso do solo urbano e a gestão de bacias hidrográficas: o caso da bacia dos rios Iguaçu/Sarapuí na Baixada Fluminense. Cadernos Metrópole, n. 19, p. 165190, jan./jun. 2008.

CARTER, N.; KREUTZWISER, R. D.; DE LOË, R. C. Closing the circle: linking land use planning and water management at the local level. Land Use Policy, v. 22, n. 2, p. 115$127,2005$.

COSTA, H. S. M. A trajetória ambiental no planejamento urbano no Brasil. In: COSTA, G. M.; MENDONÇA J. G. (Org.). Planejamento urbano no Brasil: trajetória, avanços e perspectivas. Belo Horizonte: C/Arte, 2008. p. 80-92.

COSTA, H. S. M.; CAMPANTE, A. L. G.; ARAÚJO, R. P. Z. A dimensão ambiental nos planos diretores de municípios brasileiros: um olhar panorâmico sobre a experiência recente. In: SANTOS Jr., O. A; MONTANDON, D. T. (Org.). Os planos diretores municipais Pós-Estatuto da Cidade: balanço crítico e perspectivas. Rio de Janeiro: Letra Capital; Observatório das Metrópoles, 2011. p. 173-217.
FARAH, M. F. S. Gestão pública local, novos arranjos institucionais e articulação urbano-regional. In: GONÇALVES, M. F.; BRANDÃO, C. A.; GALVÃO, A. C. F. (Org). Regiões e cidades, cidades nas regiões: o desafio urbano-regional. São Paulo: Editora Unesp; Anpur, 2003. p. 81-94.

INSTITUTO BRASILEIRO DE GEOGRAFIA E ESTATÍSTICA IBGE. Censo 2010. 2010. Disponível em: <http://www. censo2010.ibge.gov.br>. Acesso em: 11 out. 2013.

MUÑOZ ESPINOSA, H. R. (Org.) Interfaces da gestão de recursos hídricos: desafios da Lei das Águas de 1997. Brasília: Secretaria de Recursos Hídricos, 2000.

PAGNOCCHESCHI, B. Política Nacional de Recursos Hídricos. In: LITTLE, P. E (Org.). Políticas ambientais no Brasil: análises, instrumentos e experiências. Brasília: IIEB, 2003. p. 241-258.

PERES, R. B. 0 planejamento regional e urbano e a questão ambiental: análise da relação entre o plano de bacia hidrográfica Tietê-Jacaré e os planos diretores municipais de Araraquara e São Carlos, SP. 2012. 370 f. Tese de Doutorado (Engenharia Urbana) - Universidade Federal de São Carlos, São Carlos, 2012.

SILVA, R. T.; PORTO, M. F. A. Gestão urbana e gestão das águas: caminhos da integração. Estudos Avançados, São Paulo, v. 17, n. 47, p. 129-145, 2003.

Recebido: 30/07/2013

Received: 07/30/2013

Aprovado: 24/09/2013

Approved: 09/24/2013 